\title{
Dentin Erosion by Whitening Mouthwash Associated to Toothbrushing Abrasion: A Focus Variation 3D Scanning Microscopy Study
}

\author{
JULIANA P.M. LIMA, ${ }^{1}$ MARY A.S. MELO,${ }^{1}$ VANARA F. PASSOS,${ }^{1,2}$ CÍCERO L.N. BRAGA, ${ }^{1}$ LIDIANY \\ K.A. RODRIGUES, ${ }^{1}$ AND SÉRGIO L. SANTIAGO ${ }^{1 *}$ \\ ${ }^{1}$ Post-Graduate Program in Dentistry Faculty of Pharmacy Dentistry and Nursing, Federal University of Ceará, Brazil \\ ${ }^{2}$ School of Dentistry, University of Fortaleza, Fortaleza, Brazil
}

\author{
KEY WORDS dentin; erosion; mouthwashes; tooth bleaching; 3D scanning microscopy
}

\begin{abstract}
The aim of this study was to determine the erosive potential of hydrogen peroxide (HP) containing mouthwash on dentin assessed by Focus variation three-dimensional (3D) microscopy. Twenty dentin slabs were selected and randomly allocated into two groups $(n=10)$ : DW-Distilled water $(\mathrm{pH}=7.27)$ and $\mathrm{HP}-1.5 \%(\mathrm{pH}=3.78)$. Each specimen was cyclically demineralized $(4 \times 60$ s/day, 10 days) with HP or DW and brushed $3 \times /$ day ( $200 \mathrm{~g}, 150$ strokestoothpaste with $1,450 \mathrm{ppmF}$ as $\mathrm{NaF}$ ). Between the challenges, the specimens were exposed to artificial saliva. Afterward, dentin loss was analyzed using focus variation 3D microscopy, and the data were submitted to unpaired $t$-test $(\alpha=0.05)$. Statistically significant difference was found between the mean wear rate $(\mu \mathrm{m}, \pm \mathrm{SD})$ of $\mathrm{HP}(1.98 \pm 0.51)$ and $\mathrm{DW}(1.45 \pm 0.39)$. The results suggest that the use of HP-containing mouthwash associated to brushing may increase the risk of tissue loss and focus variation 3D microscopy may be used as a technique for quantifying dental wear. Microsc. Res. Tech. 76:904-908, 2013. @ 2013 Wiley Periodicals, Inc.
\end{abstract}

\section{INTRODUCTION}

Tooth-whitening treatment is the most commonly performed procedure in esthetic dentistry and is currently achieved using a large range of bleaching techniques (Hasson et al., 2006). Several techniques include the use of hydrogen peroxide $\left(\mathrm{HP} ; \mathrm{H}_{2} \mathrm{O}_{2}\right.$ ), a powerful oxidizing agent known as an effective bleaching instrument (Joiner, 2006), however, the products have different concentrations, and other different characteristics such as $\mathrm{pH}$ and application mode. Many whitening methods, which are sold legally without a dentist's prescription, are used by patients in addition to office and home bleaching techniques (Bernardon et al., 2010). These complementary approaches to improve esthetics of teeth include using toothpastes, mouthwashes or gels with whitening systems (Joiner et al., 2008). These products, usually defined as overthe-counter (OTC), are complementary alternatives to treat tooth discoloration with reduced cost compared to traditional professional or prescribed/guided techniques (Demarco et al., 2009). OTC products are whitening effective despite of demonstrating limited in-depth effect compared to supervised at-home application (Dietschi et al., 2010).

Inappropriate usage of OTC products may cause undesirable local effects, such as pulp sensitivity, gingival irritation, alterations of physical properties of some restorative materials as porosity, and slight erosion in the tooth structure (Goldberg et al., 2010). These side effects can be increased when patients use the mouthwashes more than the manufacturer's recommended regime, trying to achieve a greater or faster whitening effect without knowing the potential health hazards of peroxides. Dental esthetic satisfaction has been a concern for people of various ages (Akarslan et al., 2009; Serra et al., 2009). Consequently, the demand for using OTC whitening merchandise for this population has increased in addition to oral hygiene methods, but the use of these products can result in some effect on the mineral structure of teeth, especially in cases of exposed dentin.

Previous studies have shown that erosive wear can occur on the enamel surface following office toothwhitening treatments (Hegazy and Mubarak, 2012; Lopes et al., 2002; Yeh et al., 2005). However, other researches report that there is no change in the surface texture of the tooth, but the procedure makes the enamel surface more rough and susceptible to abrasion (Götz et al., 2007; Sulieman et al., 2004). Besides, there is no study related to erosive process in dentin by OTC whitening products. Thus, there may be a possible erosive potential in whitening mouthwash, which can be increased by its interaction with other factors involved in wear, such as dietary or endogenous acids and intraoral abrasive forces by toothbrushing.

The dentin tissue is more susceptible to acid dissolution than enamel and exhibited a wide range of erosion

\footnotetext{
*Correspondence to: Sérgio Lima Santiago, Professor, Post-Graduate Program in Dentistry, Faculty of Pharmacy, Dentistry and Nursing, Federal University of Ceará, Fortaleza, Ceará, Brazil, Rua Alexandre Baraúna, $949,3^{\circ}$ andar- Rodolfo Teófilo - Zip Code: 60430-160. E-mail: sergiosantiago@ufc.br Received 30 January 2013; accepted in revised form 26 May 2013 DOI 10.1002/jemt.22246

Published online 14 June 2013 in Wiley Online Library (wileyonlinelibrary.com).
} 
depths when different methods for analyzing dental erosion with abrasion are compared (Passos et al., 2013). The accurate characterization and measurement of hard tissue loss in dentin deserve special attention in wear investigations since the damaging effects of dental erosion are strongly influenced by interactions with abrasive forces (Wiegand et al., 2007).

Currently, there are various methods for the characterization and quantification of dental erosion. Most of them require a laborious and destructive sample preparation. The applicability of atomic force microscopy (AFM) in biological research has been considered (Barbour and Rees, 2004; De-Deus et al., 2011; Neri et al., 2011), however, AFM also has some critical limitations. The main problems were related to sample surface height variations, image acquisition speed, and the size of the scanned area (Barbour and Rees, 2004; De-Deus et al., 2011); commonly it cannot be greater than $100 \times 100 \mu^{2}$ (Loyola-Rodriguez et al., 2010). Therefore, this technique is not the most appropriate to evaluate dentin erosion, once the erosive process promotes strong height variations, that can lead to saturation in the image formation system of the AFM (De-Deus et al., 2006).

Recently, a focus variation microscope (FVM) was developed for three-dimensional (3D) topographic surface analysis (Ren et al., 2009a). FVM is a non-contact optical microscope based on the focus variation concept. This measurement is performed directly by optical imaging, causing no damage to the sample surface. Surface roughness can be calculated from the image thus obtaining morphological characterization of the substrate using 3D measurements (Fujii et al., 2011; Ren et al., 2009b). Previous reports have suggested FVM as a better choice to examine substrate changes when a less aggressive process is performed, as 3D measurements are able to give more accurate assessments than other techniques (Rodriguez and Bartlett, 2010).

Despite Medline-indexed literature data about dental wear provided by previous investigations, there is a lack of scientific information on the role of OTC whitening mouthwashes associated to toothbrushing on dentin erosion. The purpose of this study was to investigate the erosive potential of mouthwash containing $\mathrm{HP}$ in dentin slabs submitted to toothbrushing assessed by focus variation 3D scanning microscopy. The null hypothesis tested that there was no difference on the quantification of dental wear between the tested conditions on human dentin.

\section{MATERIALS AND METHODS Preparation of Dentin Specimens}

Twenty extracted, sound, third molar teeth were used to perform this in vitro study, following approval from the local Research and Ethics Committee (protocol \# 08/2011). The teeth were stored in a $0.01 \%(\mathrm{w} / \mathrm{v})$ thymol solution at $4{ }^{\circ} \mathrm{C}$ for 30 days until use (Humel et al., 2007). Dentin slabs $(4 \times 4 \times 2 \mathrm{~mm})$ were obtained from the upper third radicular portion of each tooth using a water-cooled diamond saw and a cutting machine (IsoMet Low Speed Saw, Buehler, Lake Bluff, IL). The slabs were embedded in Pre-30 self-polymerized acrylic resin cylinders to facilitate handling (Arotec SA Ind. e Com, Cotia, SP, Brazil), serially flattened with water-cooled abrasive discs (320, 600, and 1,200-grit silicon carbide), polished with felt paper and diamond paste (Metadi ${ }^{\circledR}$ Diamond Suspension 1 micron - Blue Color Polish - Water Base No. 40-6530; Buehler, Lake Bluff, IL) on a rotating polishing machine (Arotec SA Ind. e Com, Cotia, SP, Brazil,) and then identified by number and kept refrigerated.

Subsequently, in each slab, half of total area was referred as baseline area. To ensure the protection of this side (control), its surface was painted with a dark colored acid-resistant varnish (Colorama, Coml. Ind. Exp Ltda., SP, Brazil). The surface hardness was measured using Knoop microhardness tester (Future Tech FM-100, Tokyo, Japan) at a constant load of $25 \mathrm{~g}$ and dwell time of $5 \mathrm{~s}$. Five indentations were performed at the center and average value was reported as the surface hardness of the dentin slabs. This analysis was performed for selection and randomized distribution purposes. Dentin slabs presenting microhardness values ranging from 61.87 to 68.37 Knoop hardness number were randomly assigned according to a computer generated randomization list (de-Melo et al., 2011) into two groups $(n=10)$ : distilled water (DW) as a control $(\mathrm{pH}=7.27), 1.5 \% \mathrm{HP}(\mathrm{pH}=3.78)$ (Whitening Plax ${ }^{\circledR}$ Colgate - Palmolive - Ltda, Osasco, SP, Brazil; lot number: Br 122AVAL). This product contains aqua, glycerin, alcohol, HP $1.5 \%$, polysorbate 20, mentol, poloxamer 388 , methyl salicylate, menthol, and sodium saccharin.

\section{Dentin Wear Model}

The study consisted of a cyclic procedures repeated over a 10-day period, including treatment with DW or $\mathrm{HP}$, toothbrushing, treatment again, and remineralization with artificial saliva $\left(1.45 \mathrm{mM} \mathrm{Ca}^{2+}, 5.4 \mathrm{mM}\right.$ $\mathrm{PO}^{3-}{ }^{3-}, 0.1 \mathrm{M}$ Tris buffer, $2.2 \mathrm{~g} / \mathrm{L}$ porcine gastric mucin, pH 7.0; Sigma-Aldrich, St. Louis, MO) (Fig. 1).

Three times per day, the slabs were subjected to a previously published toothbrushing-abrasion protocol (Hara et al., 2008) in which all samples were positioned in the brushing machine (MSEt-1,500 W, Marcelo Nucci ME, São Carlos, SP, Brazil) and bathed with a slurry of commercially available fluoride toothpaste (Colgate Total ${ }^{\circledR} 12$ Clean Mint-1,450 ppmF as NaF; Colgate-Palmolive Ind. e Com. Ltda, SP, Brazil) and artificial saliva (1:3, w/w). Toothbrushing was achieved

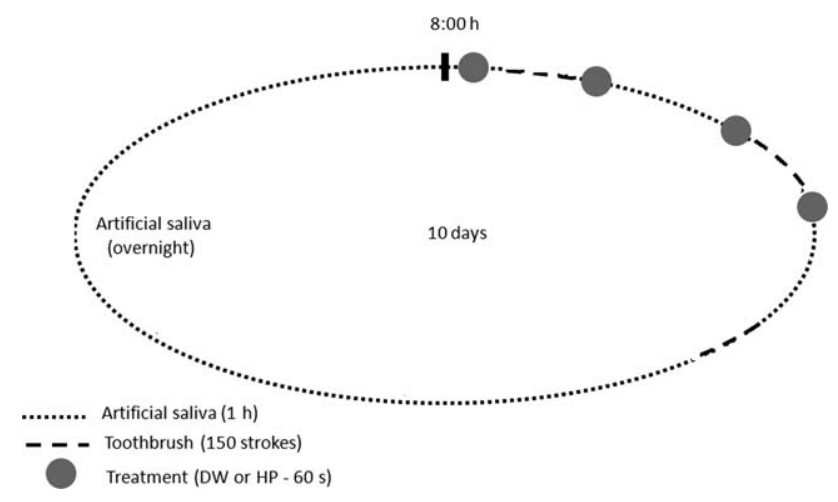

Fig. 1. 24-hour cycle followed during experiments. This sequence was repeated during 5 days. 
with a Colgate Professional Extra Clean toothbrush (Colgate-Palmolive Ind. e Com. Ltda, SP, Brazil) under a load of $200 \mathrm{~g}$ for 150 cycles at 4.5 movements per second (Hara et al., 2008).

Before and after the first and third daily toothbrushing-abrasion cycles, each specimen was independently submerged in $3 \mathrm{~mL}$ of the test solution or DW (control group) for $60 \mathrm{~s}$, under agitation, at room temperature. Afterward, the slabs were washed with DW for $10 \mathrm{~s}$ and each group was immersed in 70 $\mathrm{mL}$ of artificial saliva for 60 min using a orbital shaker table $(100 \mathrm{rpm})$. The described procedures were repeated for 10 days at a room temperature of $23 \pm$ $1^{\circ} \mathrm{C}$. The slabs were stored overnight in artificial saliva at $37^{\circ} \mathrm{C}$

Afterward, the acid resistant varnish was removed, and the surface wear was analyzed using a focus variation 3D scanning microscope.

\section{Surface 3D Topography Evaluation}

3D topography images of the dentin surfaces at magnifications of approximately $200 \times$ were captured using the InfiniteFocus ${ }^{\circledR}$ G4 Microscope (IFM, Alicona Imaging, Grambach, Graz, Austria). The non-filtered direct profile of the measurement surface was captured through computer software, and the average maximum profile height $(\mathrm{Pz}$, representing the average depth of erosion/abrasion) of the sampled profiles across the measurement length were recorded. $\mathrm{Pz}$ is the mean distances $(\mu \mathrm{m})$ from three highest peaks to the five lowest valleys, representing the mean maximum peak-to-valley distance of the sampling area. The average from three tracings of each sample was considered to reach the mean value for the group. These data were expressed as the mean and standard deviation of the surface profile for each group. IFM was also used to capture $3 \mathrm{D}$ images of the dentin surfaces where the surface roughness measurements were performed.

\section{Statistical Analysis}

Mean values of the wear per group were calculated, and the normality distribution of the data was checked using the Kolmogorov Smirnov test. The data were analyzed by unpaired $t$-test. The significance level was set at 5\%. Calculations were made using the BioStat 2007 Professional software (AnalystSoft Robust business solutions company, Vancouver, British Columbia, Canada).

\section{RESULTS}

The mean values of wear found in each group are reported in Figure 2. The results show that 1.5\% HP resulted in significantly higher wear than the control group $(P=0.01)$.

Typical surface images with control and treated areas are shown in Figure 3. After treatments with whitening mouthwash containing $1.5 \% \mathrm{HP}$, the dentin surfaces presented distinct characteristics when compared to those non-treated (Control). As shown in the profile image (Fig. 3B), there was an evident loss of tissue represented by the height of this step. Topographical images of tested area (Figs. 3A and 3C) show more

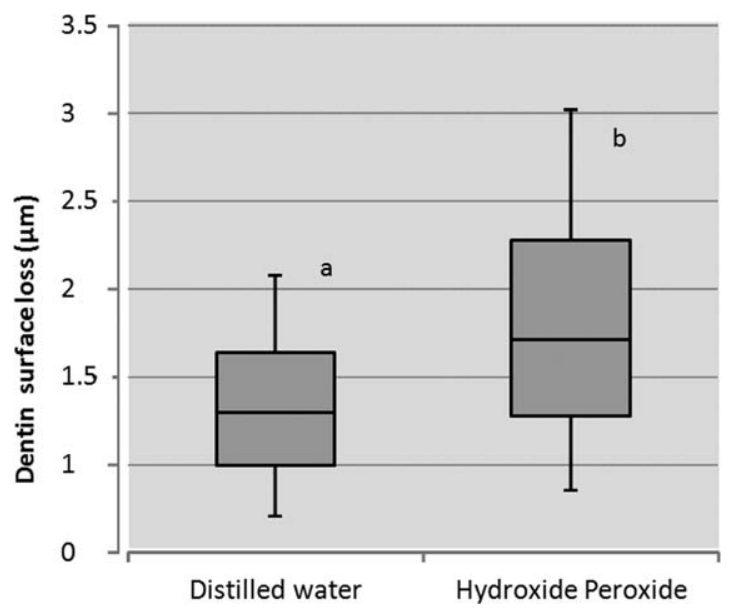

Fig. 2. Mean values of wear $(\mu \mathrm{m})$, standard deviation. * Distinct lower case letters denote significant difference among groups $(P<$ $0.05)$.

clearly the rough pattern of the eroded/abraded surface of dentin.

\section{DISCUSSION}

Mouthwashes are very popular oral hygiene products. Usually, they can act to chemically control cariogenic biofilm and provide remineralizing therapeutic approaches (Maltz, 2009). Recently, due to the rise in concern about dental esthetic appearance, a range of mouthwash products containing HP has been introduced into the market as tooth-whitening instrument (Demarco et al., 2009). However, the products of process of HP break down are relatively acid that it might affect the surface and subsurface integrity of dental tissues. This way, OTC whitening may cause hard tissue loss that may lead to the exposure of the coronary or root dentin. Furthermore, dentin tissue is more easily worn away, since in the same process the loss of dentin tissue occurs much more quickly than the loss of enamel (Gandara and Truelove, 1999). Besides, higher exposure of dentin has been observed considering the population aging and cumulative damage from years of exposure to mechanical and environmental factors such as gingival recession, abrasion, abfraction, and erosion (Vieira and Santiago, 2009).

Given this, the present in vitro study investigated the effects of a commercially available OTC whitening rinse on wear of the dentin surface using variation $3 \mathrm{D}$ scanning microscopy as tissue loss measurement method. The strength of focus variation microscopy is the ability to measure steeply sloped surfaces. However, according the ISO/DIS 25178-606 related to nominal characteristics of non-contact (focus variation) instruments, vertical resolution of approximately 100 $\mathrm{nm}$ and lateral resolution of several pixels can restrict its applicability.

The observed results indicated that the twice daily application of $1.5 \% \mathrm{HP}(\mathrm{pH}=3.78)$ performed before and after brushing resulted in a significantly higher wear rate than the control group. This lead us to reject the null hypothesis. One possible explanation for this result may be attributed to the Whitening Plax ${ }^{\circledR}$ mouthwash application protocol and $\mathrm{pH}$, since the 


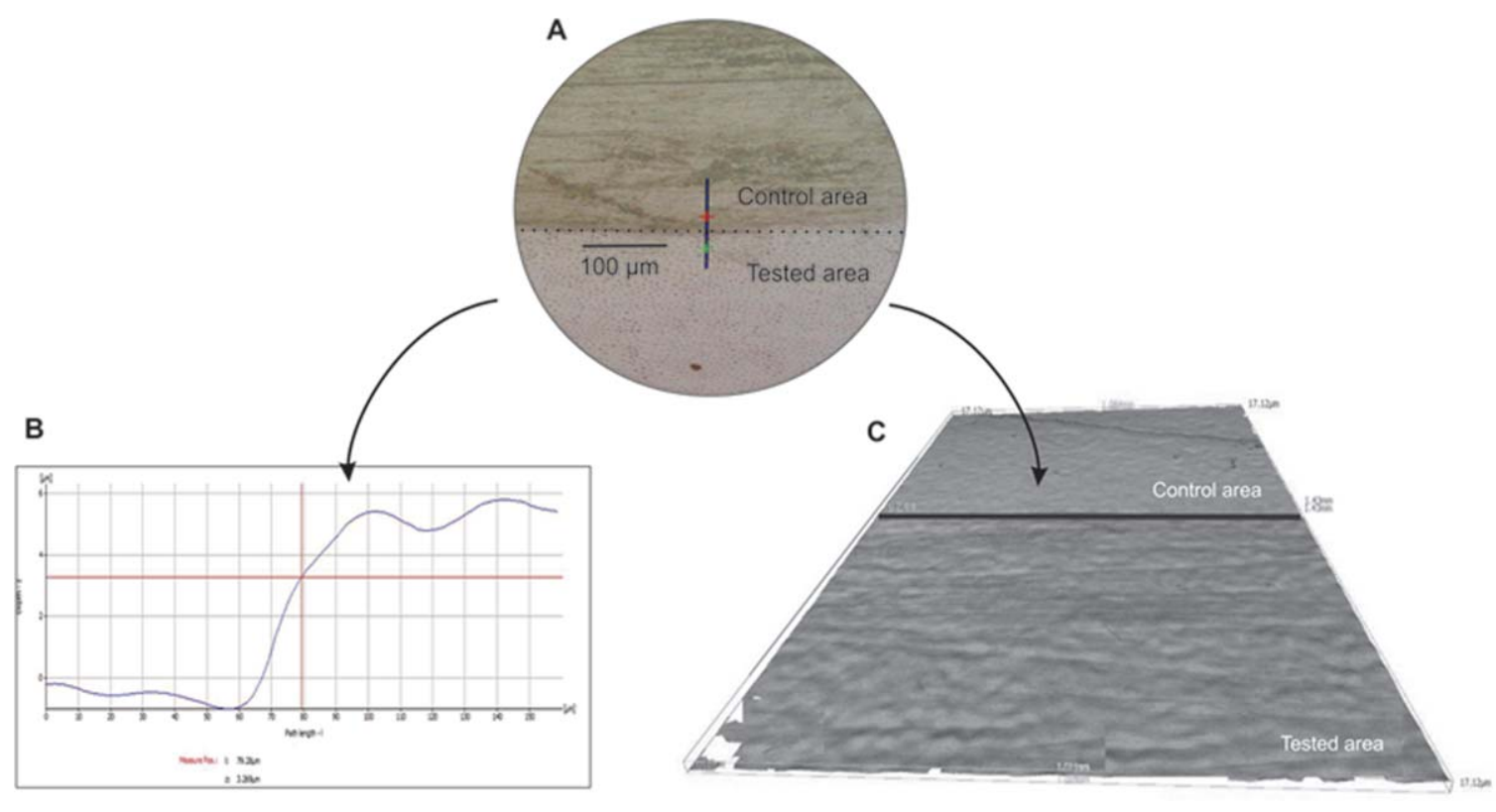

Fig. 3. A: Image of dentin surface to erosive/abrasive challenge. Hard tissue loss was visible on tested area (above). B: Profile calculated for the measured area. C: Captured 3D images of dentin interface control-tested area showing more pronounced surface changes after erosive/abrasive challenge. [Color figure can be viewed in the online issue, which is available at wileyonlinelibrary.com.]

authors decided to perform this application mode to reflect the information on the product label that is presented to users. It is also important to note that in the control group some dentin wear was found, however, statistically different from $1.5 \%$ HP group; this loss must be only due to the toothbrushing.

The erosive potential of OTC whitening mouthwash seems to be dependent of the relationship between toothbrushing and the use of the whitening solution, since accelerated loss of dental hard tissue through the combined effect of erosion and mechanical wear (abrasion) on the tooth surface was observed. Erosive challenge provided by the use of this product in relation to control (DW) results in the softening dentin, which, in combination with abrasion, results in pathological wear of this tissue.

The detrimental effects of bleaching and abrasion have been previously investigated (Engle et al., 2010; Faraoni-Romano et al., 2009; Sulieman et al., 2004). Considering the high demand for bleaching procedures and increased use of OTC whitening products, it is possible that the association of these factors would advance the dentin loss. Mainly when it has been observed in an increasing consumption of acidic foods and beverages and the availability of dentifrices with a large range of abrasive levels. A significant whole array of interacting factors including abrasive dentifrice among the factors involved in dentin wear may lead to contrasting outcomes (Engle et al., 2010). According to Engle et al. (2010), dentin loss may be modulated by the interaction of bleaching, erosion, and dentifrice. Meanwhile, Sulieman et al. (2004) using a high concentration HP (35\%) observed no deleterious effects on dentine. Probably, the difference in outcomes on dentin are most likely due to either variation in the in vitro protocols and the $\mathrm{pH}$ of products.

The selected design aimed to mimics the clinical situation related to erosive/abrasive process under the use of OTC whitening mouthwashes. It is speculated that saliva buffering capacity, content of calcium and phosphate groups, pellicle acquired on tooth surface and so forth, can act either solely or in combination to inhibit the tooth erosive procedures (Hara et al., 2008). Based on that, it was conducted the use of artificial saliva during the brushing procedures and before and after the erosive/abrasive challenge. Besides, Barbour et al., 2011 concluded that the dominant factor in erosion is $\mathrm{pH}$ and the effect of buffer capacity seems to be $\mathrm{pH}$ dependent.

According to a previous study that compared tissue loss of eroded/abraded dental hard tissues using several types of measurement methods (Passos et al., 2013), the FVM technique has been more sensitive in detecting structural changes following erosive and abrasive processes justifying the rationale use of this technique. Other study has suggested that the FVM could perform optical scans of the surface in three dimensions, and calculate surface roughness quantitatively without any surface damages. This increases the sensitive of this method including a more effective visual assessment of eroded areas (Ren et al., 2009a).

Even though these results are from an in vitro study to control mineral loss by erosive wear, dental erosion caused by OTC tooth-whitening approaches should be taken into consideration. An alternative scenario for future researches is the use of substances containing the same $\mathrm{pH}$ values, different concentrations of $\mathrm{HP}$, and testing protocols associated or not to abrasive challenges. 


\section{CONCLUSIONS}

With the limitations of this study, it can be concluded that the use of the OTC whitening mouthwash according to the manufacturer's recommendation was able to cause dentin wear more than water mouthwash. In addition, focus variation 3D microscopy seems to be a suitable method to measure dentin wear.

\section{ACKNOWLEDGMENTS}

The second and third authors thank CNPq for concession of scholarships during this study (Proc. \#141791/2010-1 and \#140643/ 2011-7, respectively). The authors have no conflict of interest to declare.

\section{REFERENCES}

Akarslan ZZ, Sadik B, Erten H, Karabulut E. 2009. Dental esthetic satisfaction, received and desired dental treatments for improvement of esthetics. Indian J Dent Res 20:195-200.

Barbour ME, Rees JS. 2004. The laboratory assessment of enamel erosion: A review. J Dent 32:591-602.

Barbour ME, Lussi A, Shellis RP. 2011. Screening and prediction of erosive potential. Caries Res 45(Suppl 1):24-32.

Bernardon JK, Sartori N, Ballarin A, Perdigão J, Lopes GC, Baratieri LN. 2010. Clinical performance of vital bleaching techniques. Oper Dent 35:3-10.

Demarco FF, Meireles SS, Masotti AS. 2009. Over-the-counter whitening agents: A concise review. Braz Oral Res 23(Suppl 1):64-70.

de-Melo MA, Passos VF, Alves JJ, Barros EB, Santiago SL, Rodrigues LK. 2011. The effect of diode laser irradiation on dentin as a preventive measure against dental erosion: An in vitro study. Lasers Med Sci 26:615-621.

Dietschi D, Benbachir N, Krejci I. 2010. In vitro colorimetric evaluation of the efficacy of home bleaching and over-the-counter bleaching products. Quintessence Int 41:505-516.

De-Deus G, Paciornik S, Pinho-Mauricio M, Prioli R. 2006. Real-time atomic force microscopy of root dentine during demineralization when subjected to chelating agents. Int Endod J 39:683-692.

De-Deus G, Reis C, Paciornik S. 2011. Critical appraisal of published smear layer-removal studies: Methodological issues. Oral Surg Oral Med Oral Pathol Oral Radiol Endod 112:531-543.

Engle K, Hara AT, Matis B, Eckert GJ, Zero DT. 2010. Erosion and abrasion of enamel and dentin associated with at-home bleaching. JADA 141:546-551.

Fujii M, Kitasako Y, Sadr A, Tagami J. 2011. Roughness and pH changes of enamel surface induced by soft drinks in vitroapplications of stylus profilometry, focus variation 3D scanning microscopy and micro pH sensor. Dent Mater J 30:404-410.

Faraoni-Romano JJ, Turssi CP, Serra MC. 2009. Effect of a $10 \%$ carbamide peroxide on wear resistance of enamel and dentine: In situ study. J Dent 37:273-278.

Gandara BK, Truelove EL. 1999. Diagnosis and management of dental erosion. J Contemp Dent Pract 1:16-23.

Goldberg M, Grootveld M, Lynch E. 2010.Undesirable and adverse effects of tooth-whitening products: A review. Clin Oral Investig 14:1-10.

Götz H, Duschner H, White DJ, Klukowska MA. 2007. Effects of elevated hydrogen peroxide 'strip' bleaching on surface and subsurface enamel including subsurface histomorphology, microchemical composition and fluorescence changes. J Dent Res 35: $457-466$.

Hara AT, González-Cabezas C, Creeth J, Zero DT. 2008. The effect of human saliva substitutes in an erosion-abrasion cycling model. Eur J Oral 116:552-556.

Hasson H, Ismail AI, Neiva G. 2006. Home-based chemically-induced whitening of teeth in adults. Cochrane Database Syst Rev 18: CD006202.

Hegazy R, Mubarak R. 2012. Is whitening pre-brush rinse a double edged weapon? Evaluation of Listerine effect on enamel microhardness and surface morphology. J Am Sci 8:126-132.

Humel MMC, Oliveira MT, Cavalli V, Giannini M. 2007. Effect of storage and disinfection methods of extracted bovine teeth on Bond strength to dentin.Braz J Oral Sci 6:1402-1406.

ISO/DIS 25178-606. 2012. Geometrical product specification (GPS)Surface texture: Areal-Part 606: Nominal characteristics of noncontact (focus variation) instruments

Joiner A. 2006. The bleaching of teeth: A review of the literature. J Dent 34:412-429.

Joiner A, Hopkinson I, Deng Y, Westland S. 2008. A review of tooth colour and whiteness. J Dent Res 36(Suppl 1):S2-S7.

Lopes GC, Bonissoni L, Baratieri LN, Vieira LC, Monteiro S, Jr. 2002 Effect of bleaching agents on the hardness and hardness and morphology of enamel. J Esthet Restor Dent 14:24-30.

Loyola-Rodriguez JP, Zavala-Alonso V, Reyes-Vela E, Patiño-Marin N, Ruiz F, Anusavice KJ. 2010. Atomic force microscopy observation of the enamel roughness and depth profile after phosphoric acid etching. J Electron Microsc 59:119-125.

Maltz M. 2009. Over-the-counter preventive and therapeutic oral products. Braz Oral Res 23:4-7.

Neri JR, Passos VF, Viana FB, Rodrigues LKA, Saboia VPA, Santiago SL. 2011. Efficacy of smear layer removal by cavity cleaning solution: An atomic force microscopy study. Rev Odonto Cienc 26:253257.

Passos VF, Melo MA, Vasconcellos AA, Rodrigues LK, Santiago SL. 2013. Comparison of methods for quantifying dental wear caused by erosion and abrasion. Microsc Res Tech 76:178-183.

Serra MC, Messias DC, Turssi CP. 2009. Control of erosive tooth wear: Possibilities and rationale. Braz Oral Res 23:49-55.

Ren YF, Zhao Q, Malmstrom H, Barnes V, Xu T. 2009a. Assessing fluoride treatment and resistance of dental enamel to soft drink erosion in vitro: Applications of focus variation $3 \mathrm{D}$ scanning microscopy and stylus profilometry. J Dent 37:167-176.

Ren YF, Amin A, Malmstrom H. 2009b. Effects of tooth whitening and orange juice on surface properties of dental enamel. J Dent 37: 424-431.

Rodriguez JM, Bartlett DW. 2010. A comparison of two-dimensional and three-dimensional measurements of wear in a laboratory investigation. Dent Mater 26:221-225.

Sulieman M, Addy M, Macdonald E, Rees JS. 2004. A safety study in vitro for the effects of an in-office bleaching system on the integrity of enamel and dentine. J Dent Res 32:581-590.

Vieira AH, Santiago SL. 2009. Management of dentinal hypersensitivity. Gen Dent 57:120.

Wiegand A, Schreier M, Attin T. 2007. Effect of different fluoridation regimes on the microhardness of bleached enamel. Oper Dent 32 : $610-615$.

Yeh ST, Su Y, Lu YC, Lee SY. 2005. Surface changes and acid dissolution of enamel after carbamide peroxide bleach treatment. Oper Dent 30:507-515 